\section{Case Reports in Ophthalmology}

Case Rep Ophthalmol 2017;8:465-474

DOI: 10.1159/000480119

Publisned onIIne: September 27, 2017

The Author(s)

Published by S. Karger AG, Basel

www.karger.com/cop

This article is licensed under the Creative Commons Attribution-NonCommercial 4.0 International License (CC BY-NC) (http://www.karger.com/Services/OpenAccessLicense) Usage and distribution for commercial purposes requires written permission.

\title{
Recurrent Diabetic Macular Edema: What to Do?
}

\author{
Rita Santos Gonçalves Carla Teixeira Pedro Coelho \\ Department of Ophthalmology, Hospital Pedro Hispano, Matosinhos, Portugal
}

\section{Keywords}

Diabetic retinopathy $\cdot$ Intravitreal injection - Macular edema $\cdot$ Visual acuity

\begin{abstract}
Diabetic macular edema (DME) is a leading cause of blindness in the working population. Herein, we report the case of a patient with recurrent DME for about 6 years, uncontrolled by several medical and surgical treatments, that was successfully treated with a single sustainedrelease fluocinolone acetonide intravitreal implant in her right eye. The affected eye had presented a visual acuity of $2 / 10$ and a central macular thickness of $488 \mu \mathrm{m}$ prior to the injection. After treatment with the fluocinolone acetonide intravitreal implant, the patient's right eye presented an improvement in best corrected visual acuity to $6 / 10$ and a reduction of central macular thickness to $198 \mu \mathrm{m}$. These functional and anatomical results were continuous and sustained during a follow-up period of more than 12 months, and with an acceptable and manageable safety profile. These results show that fluocinolone acetonide intravitreal implantation is an effective treatment option in DME and should be considered in the DME treatment pathway.




\section{Case Reports in Ophthalmology}

Case Rep Ophthalmol 2017;8:465-474

DOI: $10.1159 / 000480119$

(C) 2017 The Author(s). Published by S. Karger AG, Basel www.karger.com/cop

Gonçalves et al.: Recurrent Diabetic Macular Edema: What to Do?

\section{Introduction}

Diabetic macular edema (DME) is one of the leading causes of vision loss in the workingage population around the world [1]. It is defined by abnormal collection of extracapillary fluid due to blood-retinal barrier breakdown because of increased production of inflammatory mediators and vascular permeability factors and loss of endothelial tight junctions $[2$, 3]. Because of its complex and multifactorial pathophysiology and chronic nature, it can necessitate ongoing and numerous therapies to maintain vision.

In the past, the standard care for DME was focal/grid laser photocoagulation, but the visual acuity gain was only modest $[4,5]$. Treatments for DME are rapidly evolving, and today there are numerous alternative therapies to improve patients' vision. Inhibitors of vascular endothelium growth factor (VEGF) are currently considered as the first-line therapy of choice for DME. Several trials have shown that frequent intravitreal injections with antiVEGF were more effective than laser photocoagulation for the treatment of DME [6-8]. However, a large proportion of patients still have a poor response to anti-VEGF agents even with frequently repeated injections. In the phase III ranibizumab studies on DME (RISE and RIDE), between 30.4 and $43.2 \%$ of the patients failed to gain $\geq 10$ letters after 3 years of treatment with 0.3 or $0.5 \mathrm{mg}$ ranibizumab [6]. A recent analysis of protocol I data showed that about $40 \%$ of the eyes had a suboptimal early response $(<5$-letter improvement $)$ at 12 weeks, and most of these had suboptimal visual outcomes after 3 years of treatment [9].

Intravitreal corticosteroids have also been evaluated and shown to be effective in achieving visual gain and reduction of DME because of their ability to act on other inflammatory cytokines and pathogenic mechanisms, in addition to those associated with VEGF. Also, they can reduce the frequency of injections needed $[10,11]$. The currently available intravitreal corticosteroids for the management of DME include triamcinolone (unlicensed for DME in Europe), dexamethasone (Ozurdex ${ }^{\circledR}$; Allergan), and fluocinolone acetonide (FAc) (ILUVIEN ${ }^{\circledR}$; Alimera Sciences). Whilst the treatment effect of dexamethasone implants lasts up to 6 months, the effect of FAc implants is up to 3 years [12]. The FAME study showed that approximately one-third (34\%) of their patients with DME for $\geq 3$ years who were treated with a $0.2 \mu \mathrm{g} /$ day FAc implant experienced a $\geq 15$-letter gain, compared with $13.4 \%$ of the sham-treated patients [11].

Here, we present the case report of a patient with recurrent DME uncontrolled by several medical and surgical treatments that showed an anatomical and functional response after treatment with a single intravitreal FAc implant.

\section{Case Report}

The patient was a 61-year-old Caucasian woman with type 2 diabetes over the previous 25 years who always had good metabolic control $\left(\mathrm{HbA}_{1 \mathrm{c}}<7.5 \%\right)$. She was first diagnosed in November 2004 with bilateral incipient diabetic retinopathy. Almost 4 years after first presentation, she had decreased vision (3/10 in the right eye and 4/10 in the left eye) due to the development of cystoid macular edema (CME), which was treated at that time with focal argon grid laser in both eyes. Her best corrected visual acuity (BCVA) and CME did not improve (Fig. 1). Subsequently, the patient was treated by intravitreal injection of triamcino- 


\section{Case Reports in Ophthalmology}

lone acetonide into both eyes, with improvement of CME. In 2010, panretinal photocoagulation was started in both eyes due to proliferative diabetic retinopathy.

Despite good glycemic control, the patient's DME and proliferative retinopathy continued to develop, with decreasing BCVA. In August 2011, the patient's CME increased and BCVA decreased again (1/10 in both eyes). She underwent multiple triamcinolone acetonide injections into both eyes with partial and transitory responses (Fig. 2). A transient increase in intraocular pressure (IOP) was observed after intravitreal triamcinolone injection.

In November 2012, the left eye underwent pars plana vitrectomy combined with phacoemulsification due to vitreous hemorrhage and cataract development, respectively. After the surgical procedure, the development of central retinal atrophy (central foveal thickness of $195 \mu \mathrm{m}$ ) and a BCVA of $0.5 / 10$ in the left eye were verified, results which remained stable over the follow-up period. The right eye also underwent phacoemulsification due to cataract development, combined with intravitreal triamcinolone. Postoperatively, the right eye's BCVA increased to 6/10 and the macula became dry.

In September 2013, the right eye developed CME again and the BCVA dropped to 2/10. The patient received a loading dose of 3 intravitreal injections of ranibizumab with an increase in BCVA to 5/10, but with recurrence of CME 4 months later. Up to 2015, alternate intravitreal injections of ranibizumab and triamcinolone acetonide were performed on the right eye, without sustained functional or anatomical results.

In September 2015, an FAc intravitreal implant was placed in the right eye, with resolution of the CME (the central foveal thickness decreased from $488 \mu \mathrm{m}$ prior to the injection to $198 \mu \mathrm{m}$ after treatment) and an increase in BCVA (from 2/10 to 6/10 after the injection) 1 month later, results that remain stable 12 months later (Fig. 3). Table 1 summarizes the treatments performed on the right eye for DME, and the respective outcomes, from the diagnosis of diabetic retinopathy to the present date.

As in the last year intercurrences occurred in the right eye, we reported the occurrence of vitreous hemorrhage after posterior vitreous detachment, which resolved spontaneously. Additional laser treatment was performed for enhancement of the panretinal photocoagulation. Moreover, we reported ocular hypertension in the right eye (max. IOP $=27 \mathrm{~mm} \mathrm{Hg}$ ), which was effectively controlled with hypotensive eye drops and selective laser trabeculoplasty (SLT) (Table 1), without any documented damage to the optic nerve.

\section{Discussion}

Due to its chronic nature and persistence, DME can be difficult to manage. Combined medical and even surgical procedures may be the best way to achieve DME control in patients. Use of an FAc intravitreal implant, a slow-release low-dose corticosteroid implant, is indicated for the treatment of vision impairment associated with chronic DME considered insufficiently responsive to available therapies, and it is the only treatment available with a treatment regimen of 1 single injection for up to 36 months [11], which suggests a reduced treatment burden.

The patient whose case we reported is a challenge to any ophthalmologist that treats DME. Despite having good metabolic control and despite the various treatments administered, which included both laser treatment and intravitreal injections of anti-VEGF agents 
and short-term-efficacy corticosteroids, she had not responded sufficiently, and chronic DME over a period of about 6 years as well as progressive aggravation of her visual function were observed. Thus, an alternative treatment was required, since the right eye was the only one with potential visual function and prolonged intraretinal fluid accumulation might have caused irreversible damage resulting in permanent visual loss. In this case, the switch to an FAc intravitreal implant in the right eye appears to have been an excellent therapeutic option, with rapid resolution of the CME and a significant increase in BCVA after injection of the implant. It also allowed the patient to remain free of DME and to achieve a good functional vision of $6 / 10$ for more than 12 months, with an acceptable and manageable safety profile.

In recent years, there have been numerous clinical studies reporting the efficacy and safety of the FAc implant in patients whose DME has been insufficiently responsive to laser therapy and intravitreal anti-VEGF agents [13-17]. As an example, Alfaqawi et al. [14] showed, at 12 months, a mean improvement of +8 letters from baseline and a gain of $\geq 15$ ETDRS letters in $25 \%$ of their patients. This kind of emerging evidence has been vital for clinicians to justify the use of the FAc implant in those patients who have not responded to the first-line therapy of DME.

This case report also demonstrates the potential effectiveness of the FAc intravitreal implant in a real-world clinical setting and suggests that it should be considered if a patient does not respond optimally to other available therapies. Notably, in this case, we observed that a prior steroid response to intravitreal triamcinolone predicted a subsequent response to the FAc implant, including patient IOP outcomes. Recently, Bailey et al. [18] have already shown that emergent IOP-lowering medication or IOP elevation above $30 \mathrm{~mm}$ Hg following treatment with FAc was more frequently reported in patients with prior IOP-related events. In our case, SLT was successfully utilized in the management of ocular hypertension, which may suggest a potential role for SLT as a less-invasive treatment for the management of IOP elevation associated with FAc treatment.

\section{Statement of Ethics}

Patient consent and hospital ethics committee approval were obtained.

\section{Disclosure Statement}

The authors report no conflicts of interest.

\section{References}

1 Yau JW, Rogers SL, Kawasaki R, Lamoureux EL, Kowalski JW, Bek T, et al: Global prevalence and major risk factors of diabetic retinopathy. Diabetes Care 2012;35:556-564.

2 Bhagat N, Grigorian RA, Tutela A, Zarbin MA: Diabetic macular edema: pathogenesis and treatment. Surv Ophthalmol 2009;54:1-32.

-3 Nguyen QD, Tatlipinar S, Shah SM, Haller JA, Quinlan E, Sung J, et al: Vascular endothelial growth factor is a critical stimulus for diabetic macular edema. Am J Ophthalmol 2006;142:961-969. 
Photocoagulation for diabetic macular edema. Early Treatment Diabetic Retinopathy Study report number 1. Early Treatment Diabetic Retinopathy Study research group. Arch Ophthalmol 1985;103:1796-1806. Group: The RESTORE study: ranibizumab monotherapy or combined with laser versus laser monotherapy for diabetic macular edema. Ophthalmology 2011;118:615-625. Brown DM, Nguyen QD, Marcus DM, Boyer DS, Patel S, Feiner L, et al: Long-term outcomes of ranibizumab therapy for diabetic macular edema: the 36-month results from two phase III trials: RISE and RIDE. Ophthalmology 2013;120:2013-2022.

Elman MJ, Ayala A, Bressler NM, Browning D, Flaxel CJ, Glassman AR, et al: Intravitreal ranibizumab for diabetic macular edema with prompt versus deferred laser treatment: 5-year randomized trial results. Ophthalmology 2015;122:375-381.

-8 Rajendram R, Fraser-Bell S, Kaines A, Michaelides M, Hamilton RD, Esposti SD, et al: A 2-year prospective randomized controlled trial of intravitreal bevacizumab or laser therapy (BOLT) in the management of diabetic macular edema: 24-month data: report 3. Arch Ophthalmol 2012;130:972979.

Gonzalez VH, Campbell J, Holekamp NM, Kiss S, Loewenstein A, Augustin AJ, et al: Early and long-term responses to anti-vascular endothelial growth factor therapy in diabetic macular edema: analysis of protocol I data. Am J Ophthalmol 2016;172:72-79.

10 Diabetic Retinopathy Clinical Research Network, Chew E, Strauber S, Beck R, Aiello LP, Antoszyk A, Bressler N, et al: Randomized trial of peribulbar triamcinolone acetonide with and without focal photocoagulation for mild diabetic macular edema: a pilot study. Ophthalmology 2007;114:1190-1196. Campochiaro PA, Brown DM, Pearson A, Chen S, Boyer D, Ruiz-Moreno J, et al: Sustained delivery fluocinolone acetonide vitreous inserts provide benefit for at least 3 years in patients with diabetic macular edema. Ophthalmology 2012;119:2125-2132.

12 Stewart MW, Flynn HW Jr, Schwartz SG, Scott IU: Extended duration strategies for the pharmacologic treatment of diabetic retinopathy: current status and future prospects. Expert Opin Drug Deliv 2016;13:1277-1287.

13 Elaraoud I, Attawan A, Quhill F: Case series investigating the efficacy and safety of bilateral fluocinolone acetonide (ILUVIEN ${ }^{\circledR}$ ) in patients with diabetic macular edema. Ophthalmol Ther 2016;5:95-104.

14 Alfaqawi F, Lip PL, Elsherbiny S, Chavan R, Mitra A, Mushtaq B: Report of 12 months efficacy and safety of intravitreal fluocinolone acetonide implant for the treatment of chronic diabetic macular oedema: $\mathrm{a}$ real-world result in the United Kingdom. Eye (Lond) 2017;31:650-656.

15 Bertelmann T, Schulze S: Long-term follow-up of patient with diabetic macular edema receiving fluocinolone acetonide intravitreal implant. Ophthalmol Ther 2015;4:51-58.

16 Massin P, Erginay A, Dupas B, Couturier A, Tadayoni R: Efficacy and safety of sustained-delivery fluocinolone acetonide intravitreal implant in patients with chronic diabetic macular edema insufficiently responsive to available therapies: a real-life study. Clin Ophthalmol 2016;10:1257-1264.

17 Schmit-Eilenberger VK: A novel intravitreal fluocinolone acetonide implant (ILUVIEN ${ }^{\circledR}$ ) in the treatment of patients with chronic diabetic macular edema that is insufficiently responsive to other medical treatment options: a case series. Clin Ophthalmol 2015;9:801-811.

-18 Bailey C, Chakravarthy U, Lotery A, Menon G, Talks J; Medisoft Audit Group: Real-world experience with $0.2 \mu \mathrm{g}$ /day fluocinolone acetonide intravitreal implant (ILUVIEN) in the United Kingdom. Eye (Lond) 2017, Epub ahead of print. 


\section{Case Reports in Ophthalmology}

www.karger.com/cop
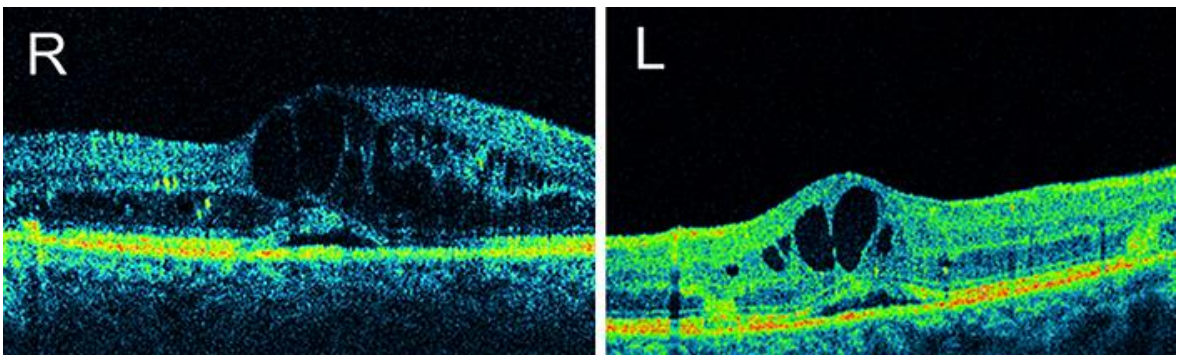

Fig. 1. OCT. Bilateral extensive cystoid macular edema and subfoveal neurosensory retinal detachment after laser photocoagulation (September 2009). 


\section{Case Reports in Ophthalmology}

Case Rep Ophthalmol 2017;8:465-474

(C) 2017 The Author(s). Published by S. Karger AG, Basel www.karger.com/cop

Gonçalves et al.: Recurrent Diabetic Macular Edema: What to Do?
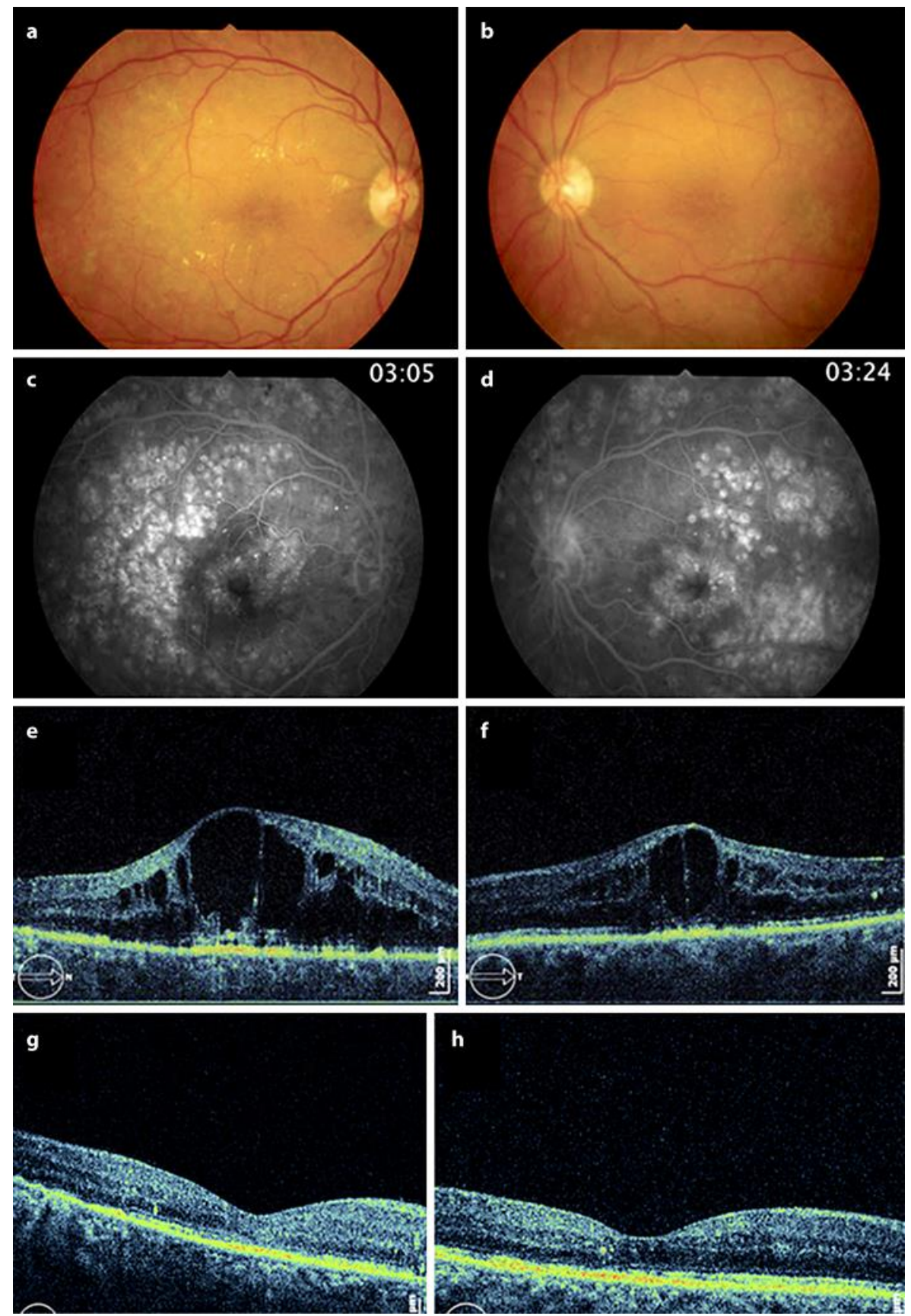

Fig. 2. a-f Prior to injections (August 2011). a-d Retinography and fluorescein angiography. Bilateral severe diabetic macular edema with hard exudates in the right eye; there are visible scars after panretinal photocoagulation. e, f OCT. Extensive CME with huge intraretinal cysts. $\mathbf{g}$, $\mathbf{h}$ After intravitreal triamcinolone injections (October 2011). OCT images. Right eye with few cysts and left eye with a dry macula. 


\section{Case Reports in Ophthalmology}
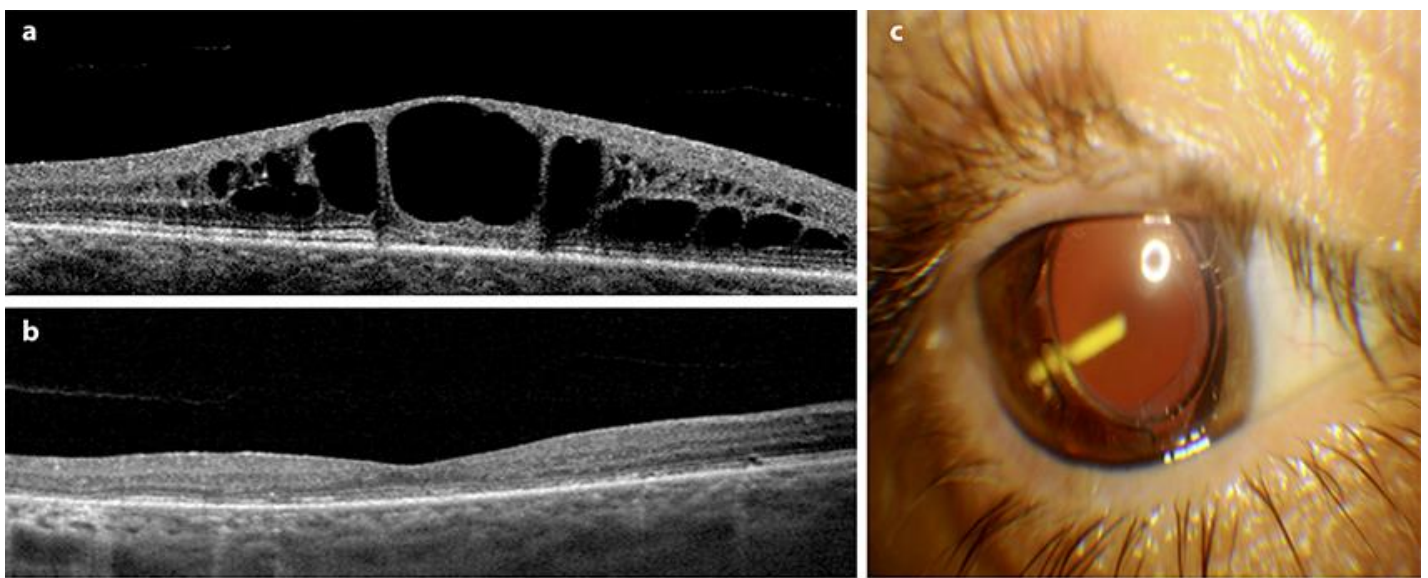

d

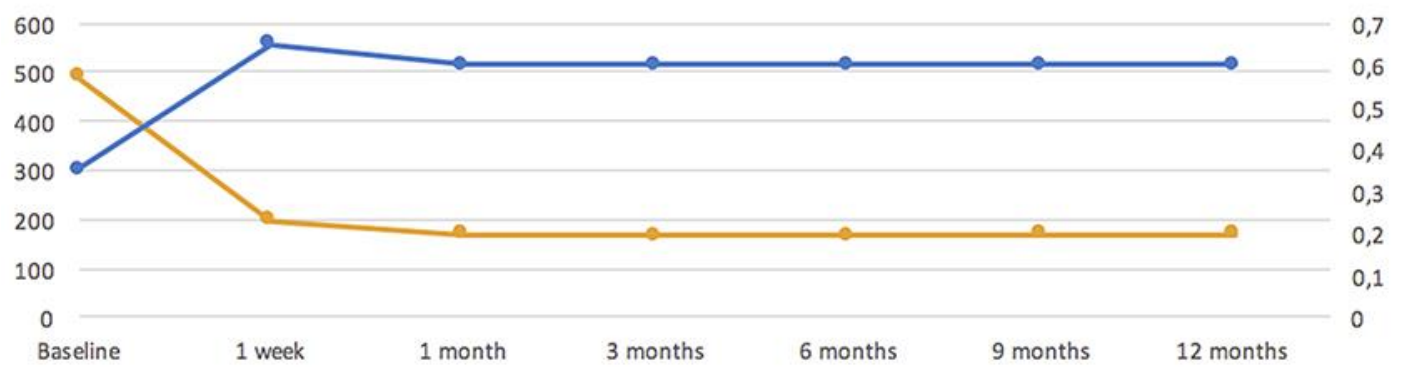

$\leadsto \mathrm{CMT}(\mu \mathrm{m}) \leadsto$ BCVA

Fig. 3. a OCT. Cystoid macular edema in the right eye prior to injection of the fluocinolone acetonide implant (July 2015). b OCT. Dry macula of the right eye 1 month following treatment with the fluocinolone acetonide implant (October 2015). c Visualization of the intravitreal fluocinolone implant in the patient's right eye at the day of injection. $\mathbf{d}$ Graph showing the change in best corrected visual acuity (BCVA) and central macular thickness (CMT) following injection of the fluocinolone acetonide implant. 
Table 1. Summary of the treatments performed for DME in the right eye of the patient

\begin{tabular}{|c|c|c|c|c|}
\hline Date & Description & VA & $\begin{array}{l}\text { CFTa, } \\
\mu \mathrm{m}\end{array}$ & $\begin{array}{l}\text { IOP, } \\
\mathrm{mm} \mathrm{Hg}\end{array}$ \\
\hline $11 / 2004$ & Incipient diabetic retinopathy diagnosed & $10 / 10$ & $\mathrm{NN}$ & 17 \\
\hline $03 / 2008$ & Moderate nonproliferative diabetic retinopathy & $9 / 10$ & $\mathrm{NN}$ & 14 \\
\hline $04 / 2008$ & Focal laser photocoagulation & & & \\
\hline $03 / 2009$ & DME diagnosed & $3 / 10$ & 492 & $\mathrm{NN}$ \\
\hline $05 / 2009$ & Macular grid laser & & & \\
\hline $09 / 2009$ & Visit & $3 / 10$ & 512 & $\mathrm{NN}$ \\
\hline $10 / 2009$ & IVTA injection & & & \\
\hline $11 / 2009$ & Visit & $4 / 10$ & 302 & 18 \\
\hline $06 / 2010$ & Proliferative diabetic retinopathy diagnosed & & & 16 \\
\hline $07 / 2010$ & Panretinal photocoagulation & & & \\
\hline $12 / 2010$ & Visit & $3 / 10$ & 315 & 16 \\
\hline $05 / 2011$ & Proliferative diabetic retinopathy progression & & & 17 \\
\hline $06 / 2011$ & Reinforcement of panretinal photocoagulation & & & \\
\hline $08 / 2011$ & Visit & $1 / 10$ & 664 & 14 \\
\hline $09 / 2011$ & IVTA injection & & & 14 \\
\hline $10 / 2011$ & Visit & $5 / 10$ & 308 & 20 \\
\hline $01 / 2012$ & Visit & $1 / 10$ & 540 & 17 \\
\hline $03 / 2012$ & IVTA injection & & & \\
\hline $04 / 2012$ & Visit & $5 / 10$ & 268 & $26^{b}$ \\
\hline $05 / 2012$ & Visit & $5 / 10$ & NN & 14 \\
\hline $08 / 2012$ & Visit & $3 / 10$ & 420 & 14 \\
\hline $09 / 2012$ & IVTA injection & & & \\
\hline $02 / 2013$ & Dense cataract & $1 / 10$ & $\mathrm{NN}$ & 18 \\
\hline $04 / 2013$ & Cataract surgery + IVTA injection & & & \\
\hline $05 / 2013$ & Visit & $5 / 10$ & 287 & 18 \\
\hline $07 / 2013$ & Visit & $6 / 10$ & 292 & 20 \\
\hline $09 / 2013$ & Visit & $2 / 10$ & 454 & $\mathrm{NN}$ \\
\hline $10-11 / 2013$ & 3 intravitreal injections of ranibizumab & & & \\
\hline $12 / 2013$ & Visit & $5 / 10$ & 270 & $\mathrm{NN}$ \\
\hline $02 / 2014$ & Visit & $4 / 10$ & 480 & $\mathrm{NN}$ \\
\hline $04 / 2014$ & IVTA injection & & & \\
\hline $05 / 2014$ & Visit & $5 / 10$ & 290 & \\
\hline $07 / 2014$ & Visit & $2 / 10$ & 520 & \\
\hline $09-11 / 2014$ & 3 intravitreal injections of ranibizumab & & & \\
\hline $12 / 2014$ & Visit & $3 / 10$ & 360 & \\
\hline $01 / 2015$ & Visit & $1 / 10$ & 458 & \\
\hline $04 / 2015$ & IVTA injection & & & \\
\hline $05 / 2015$ & Visit & $5 / 10$ & 262 & 15 \\
\hline $07 / 2015$ & Visit & $2 / 10$ & 488 & 23 \\
\hline $09 / 2015$ & Fluocinolone acetonide intravitreal implant injection & & & \\
\hline $10 / 2015$ & Visit & $6 / 10$ & 198 & 14 \\
\hline $12 / 2015$ & Visit & $6 / 10$ & 169 & 21 \\
\hline $03 / 2016$ & Visit & $6 / 10$ & 167 & $27 c$ \\
\hline $09 / 2016$ & Visit & $6 / 10$ & 168 & 22 \\
\hline
\end{tabular}


$01 / 2017 \quad$ Visit

$03 / 2017$
10/2016 Visit

$\begin{array}{lll}6 / 10 & \text { NN } & 27^{d} \\ 6 / 10 & \text { NN } & 24^{\mathrm{e}} \\ 6 / 10 & 208 & 18\end{array}$

CFT, central foveal thickness; DME, diabetic macular edema; IOP, intraocular pressure; IVTA, intravitreal triamcinolone acetonide; NN, no numbers; VA, visual acuity. a Spectral domain OCT Copernicus ${ }^{\circledR}$ (Optopol) until end of 2014 and Avanti RTVue XR ${ }^{\circledR}$ (Optovue) after that. ${ }^{\mathrm{b}}$ Here the patient was medicated with eye drops of timolol and dorzolamide for 2 months. c The patient started treatment with eye drops of timolol and dorzolamide. ${ }^{\mathrm{d}}$ Brimonidine was added to the topical hypotensive treatment. $\mathrm{e}$ The patient underwent selective laser trabeculoplasty after this visit, keeping the hypotensive eye drops. 